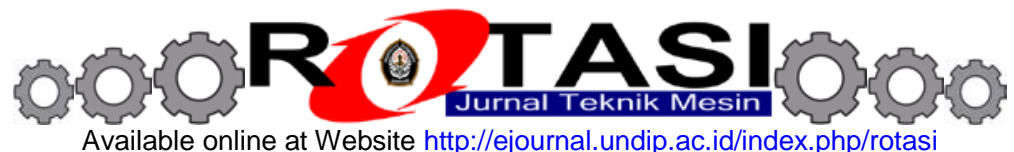

\title{
STUDI KETAHANAN BALISTIK BAJA HIGH STRENGTH LOW ALLOY AISI 4140
}

\author{
* Rusnaldy, Herlangga \\ Departemen Teknik Mesin, Fakultas Teknik, Universitas Diponegoro \\ Jl. Prof. Soedarto, SH Kampus Undip Tembalang, Semarang, Indonesia \\ *Email: rusnaldy@undip.ac.id
}

\begin{abstract}
ABSTRAK
Baja adalah material yang mudah diperoleh dan relatif murah harganya. Selama ini material tahan peluru yang digunakan untuk membuat kendaraan tempur (Tank) masih berasal dari negara lain. Baja yang digunakanpun kebanyakan adalah dari jenis baja armor atau baja khusus untuk menahan serangan peluru. Pada studi ini baja komersial yang terdapat di pasaran digunakan untuk diteliti kemampuannya dalam menahan peluru. Jenis baja tersebut adalah jenis baja high strength low alloy (HSLA) AISI 4140. Agar dapat menahan peluru, baja tersebut perlu ditingkatkan kekuatan dan kekerasannya melalui proses perlakuan panas. Disamping itu perlu dicari berapa ketebalan minimum dari baja jenis ini yang masih dapat menahan penetrasi peluru. Uji balistik dilakukan di lapangan tembak markas Brimob di Semarang. Uji tembak dilakukan oleh personil Brimob yang memiliki keahlian menembak dari jarak jauh (sniper) dengan menggunakan senjata AK 101 yang mampu melontarkan peluru dengan kecepatan $900 \mathrm{~m} / \mathrm{s}$. Peluru yang digunakan memiliki kaliber 5,6 mm dengan jarak tembak $25 \mathrm{~m}$. Setelah uji tembak, dilakukan pengamatan terhadap jenis kerusakan yang terjadi pada pelat target. Dari hasil pengujian didapatkan bahwa proses perlakuan panas hardening dapat meningkatkan ketahanan peluru baja AISI 4140, dimana ketebalan minimum pelat yang masih dapat menahan peluru adalah $7 \mathrm{~mm}$.
\end{abstract}

Kata kunci: Baja, AISI 4140, Ketahanan Balistik, Uji Tembak

\section{PENDAHULUAN}

Baja adalah material yang mudah didapat dan harganya relatif murah bila dibandingkan dengan material lain yang digunakan untuk material tahan peluru. Untuk kendaraan tempur militer penggunaan baja masih relatif dominan penggunaannya namun upaya-upaya tetap terus dilakukan untuk memperoleh baja yang setipis mungkin tetapi masih memiliki ketahanan balistik yang baik sehingga kendaraan tempur dapat dibuat menjadi lebih ringan.

Disamping itu kombinasi sifat baja seperti kekuatan yang tinggi yang dikombinasikan dengan ketangguhan yang baik serta harganya yang murah masih membuat baja menjadi pilihan utama material logam untuk material armor [1]. Komposisi kimia baja dan proses perlakuan panas dapat digunakan untuk memodifikasi baja karena akan mempengaruhi sifat mekanik dan performan balistik dari baja [1-10].

Disamping baja khusus untuk material armor, baja high strength low alloy (HSLA) juga banyak digunakan untuk material tahan peluru [8]. Hal ini karena baja jenis ini memiliki sifat mekanik yang superior, mampu mesin yang baik, performan yang tinggi dan harganya yang murah. Untuk itu pada studi kali ini material HSLA yang banyak dijual di pasaran, yaitu AISI 4140, digunakan untuk dilihat ketahanan balistiknya. Untuk meningkatkan kekerasannya proses perlakuan panas hardening diterapkan. Kemudian diteliti hingga setebal berapa baja tersebut masih mampu menahan penetrasi dari peluru. Hasil dari studi ini nantinya akan dijadikan sebagai dasar untuk mendesain dan membuat sendiri baja yang memiliki ketahanan balistik yang baik

\section{METODOLOGI PENELITIAN}

Baja AISI 4140 yang banyak dijual di pasaran digunakan pada studi ini. Namun baja yang tersedia adalah dalam bentuk batangan silinder dengan diameter bervariasi. Baja batangan dengan diameter $20 \mathrm{~mm}$ dipilih sebagai material benda kerja atau material target. Kemudian dilakukan proses permesinan untuk mendapatkan material benda kerja dengan tebal $9 \mathrm{~mm}, 7 \mathrm{~mm}$ dan $5 \mathrm{~mm}$.

Proses perlakuan panas yang dilakukan pada dasarnya adalah untuk meningkatkan kekuatan dan kekerasan baja. Baja dipanaskan hingga mencapai temperatur austenit $\left(950^{\circ} \mathrm{C}\right)$ kemudian ditahan hingga 30 menit pada temperatur tersebut di dalam suatu tungku perlakuan panas. Proses pendinginan dilakukan dengan mencelupkan baja yang diambil dari dapur perlakuan panas ke dalam air. Fasa martensit yang keras diharapkan dapat terbentuk dari proses perlakuan panas ini. Kemudian dilakukan pengamatan struktur mikro dan pengujian kekerasan pada pelat baja baik setelah maupun sebelum dilakukan proses perlakuan panas.

Pengujian tembak dilakukan di lapangan tembak markas Brimob Semarang. Pengujian dilakukan oleh seorang anggota Brimob yang memiliki keahlian sebagai penembak jarak jauh (sniper). Senapan yang digunakan adalah AK 101 kaliber 5,56 dengan kecepatan tembak $900 \mathrm{~m} / \mathrm{s}$. Jarak tembak yang digunakan sesuai standar pengujian yang biasa dilakukan oleh PT. Pindad yaitu sebesar $25 \mathrm{~m}$. Sementara peluru yang digunakan adalah jenis MU4-TJ dengan kaliber $5,56 \mathrm{~mm}$. Sebelum dilakukan uji tembak pada pelat, kecepatan peluru diukur terlebih dahulu dengan menggunakan alat chronograph digital. 


\section{HASIL DAN PEMBAHASAN}

Komposisi kimia dari baja HSLA AISI 4140 yang digunakan dapat dilihat pada tabel 1. Sementara data hasil pengujian kekerasannya dapat dilihat pada tabel 2. Dari data terlihat bahwa proses perlakuan panas hardening, yaitu dengan proses quenching yang dilakukan ke dalam air menghasilkan peningkatan kekerasan hampir 100\%, dari rata-rata 325 HB menjadi 615 HB. Nilai kekerasan sebesar 615 HB sudah cukup melampaui nilai kekerasan minimum sebesar 500 HB yang merupakan syarat suatu baja untuk baja armor.

Tabel 1. Hasil Pengujian Komposisi Kimia Pelat

\begin{tabular}{|c|c|c|c|c|c|c|c|c|c|c|c|c|}
\hline Unsur & $\mathrm{C}$ & $\mathrm{Si}$ & $\mathrm{Mn}$ & $\mathrm{P}$ & $\mathrm{S}$ & $\mathrm{Cr}$ & $\mathrm{Ni}$ & $\mathrm{Mo}$ & $\mathrm{Sn}$ & $\mathrm{Al}$ & $\mathrm{Cu}$ & $\mathrm{Fe}$ \\
\hline \%Berat & 0,42 & 0,25 & 0,74 & 0,01 & 0,023 & 1,14 & 0,02 & 0,2 & 0,026 & 0,0317 & 0,1 & Balance \\
\hline
\end{tabular}

Tabel 2. Hasil Pengujian Kekerasan Pelat Baja

\begin{tabular}{|c|c|c|}
\hline $\begin{array}{c}\text { Titik } \\
\text { Pengujian }\end{array}$ & $\begin{array}{c}\text { Nilai Kekerasan Sebelum Proses } \\
\text { Hardening (HB) }\end{array}$ & $\begin{array}{c}\text { Nilai Kekerasan Setelah Proses Hardening } \\
\text { (HB) }\end{array}$ \\
\hline 1 & 327 & 615 \\
\hline 2 & 327 & 595 \\
\hline 3 & 327 & 634 \\
\hline 4 & 327 & 615 \\
\hline 5 & 319 & 615 \\
\hline Rata-rata & 325 & $\mathbf{6 1 5}$ \\
\hline
\end{tabular}

Struktur mikro baja AISI 4140 sebelum dan setelah proses perlakuan panas dapat dilihat pada gambar 1 dan 2 . Dari gambar 1, terlihat bahwa struktur mikro baja terdiri dari ferit yang berwarna putih dan sementit yang berwarna hitam. Setelah proses perlakuan panas, struktur mikro didominasi oleh fasa martensit yang keras yang berwarna hitam dan austenit sisa yang berwarna putih. Perubahan struktur mikro ini yang menyebabkan naiknya nilai kekerasan baja menjadi hampir $100 \%$.

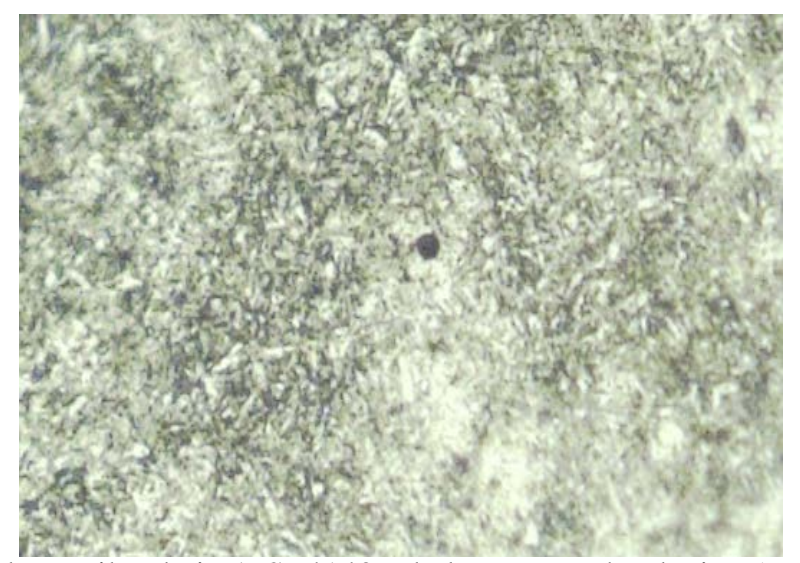

Gambar 1. Struktur mikro baja AISI 4140 sebelum proses hardening (perbesaran 200X).

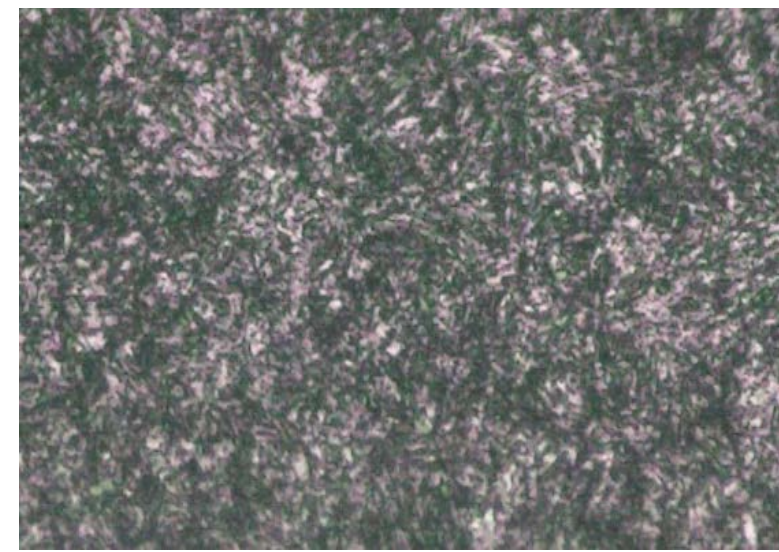

Gambar 2. Struktur mikro baja AISI 4140 setelah proses hardening (perbesaran 200X).

Hasil uji tembak yang dilakukan dapat dirangkum pada tabel 3. Perbandingan hasil uji juga dilakukan dengan baja dari jenis karbon rendah dan baja tahan karat SS 304. Dari hasil uji tembak terlihat bahwa baja AISI 4140 dengan 
tebal 9 mm tidak dapat ditembus oleh peluru kaliber 5,56 mm yang ditembak dengan kecepatan $900 \mathrm{~m} / \mathrm{s}$. Sementara dua baja komersial yang lain, yaitu baja karbon rendah dan baja tahan karat SS 304 berhasil ditembus oleh peluru.

Sementara itu ketika baja AISI 4140 dikeraskan dengan perlakuan panas hardening, kekerasan yang naik hingga mencapai $100 \%$ juga mampu meningkatkan baja untuk menahan peluru. Bentuk crater yang dihasilkan lebih dangkal dibanding crater yang dihasilkan pada pelat baja yang tidak mengalami hardening, dan hanya berupa bekas indentasi. Perlakuan panas hardening juga menyebabkan baja mampu menahan peluru pada ketebalan yang lebih tipis yaitu 7 mm. Namun pada ketebalan 5 mm, peluru yang ditembakkan menyebabkan baja menjadi pecah.

Tabel 3. Hasil uji tembak

\begin{tabular}{|c|c|c|c|}
\hline Jenis Baja & Tebal Pelat (mm) & Proses Hardening & Hasil \\
\hline AISI 4140 & 9 & Tidak & Tidak Tembus \\
\hline AISI 4140 & 9 & Iya & Tidak Tembus \\
\hline AISI 4140 & 7 & Iya & Tidak Tembus \\
\hline AISI 4140 & 5 & Iya & Pecah \\
\hline Low Carbon Steel & 9 & Tidak & Tembus \\
\hline SS 304 & 9 & Tidak & Tembus \\
\hline
\end{tabular}
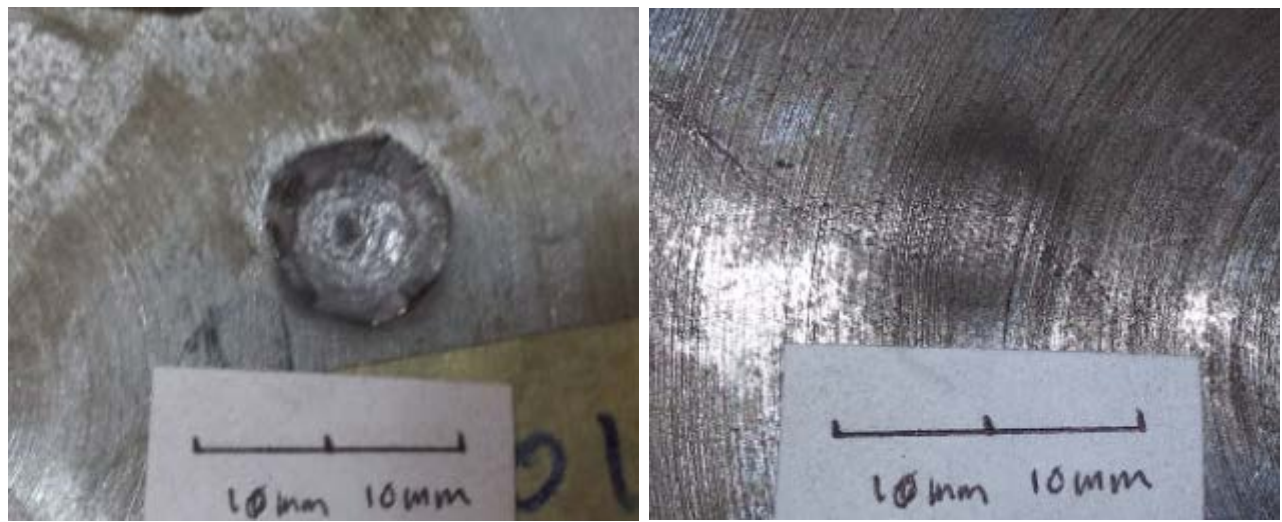

Gambar 3. Kerusakan Pada Pelat Baja AISI 4140. Kiri bagian depan dan Kanan bagian belakang
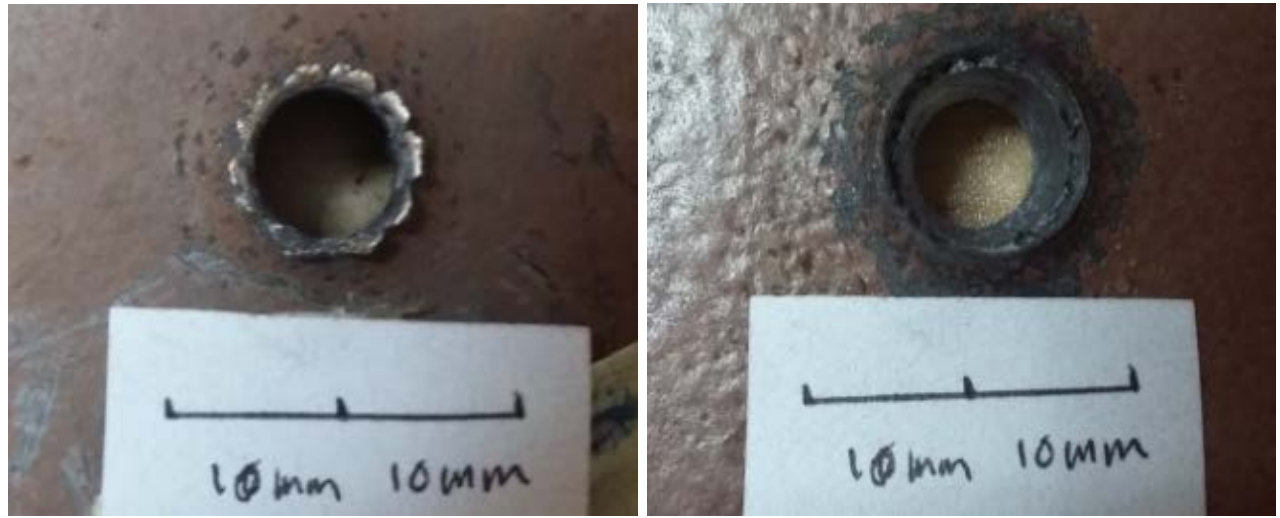

Gambar 4. Kerusakan Pada Pelat Baja Karbon Rendah. Kiri bagian depan dan Kanan bagian belakang
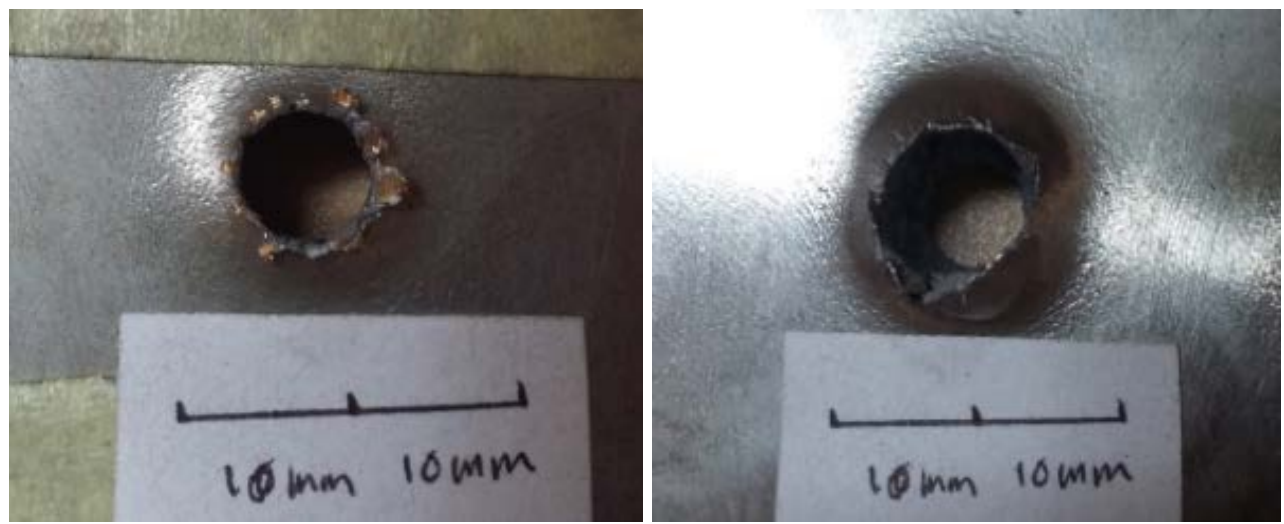

Gambar 5. Kerusakan Pada Pelat Baja SS 304. Kiri bagian depan dan Kanan bagian belakang 


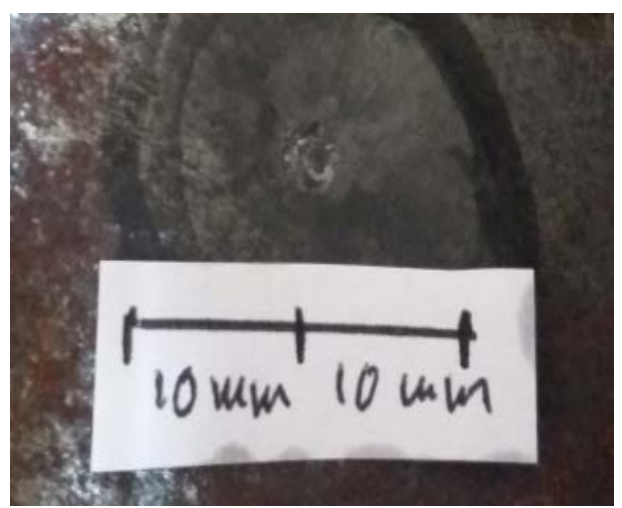

Gambar 6. Kerusakan Pada Pelat Baja AISI 4140 setelah Proses Hardening dengan tebal pelat 9 mm.

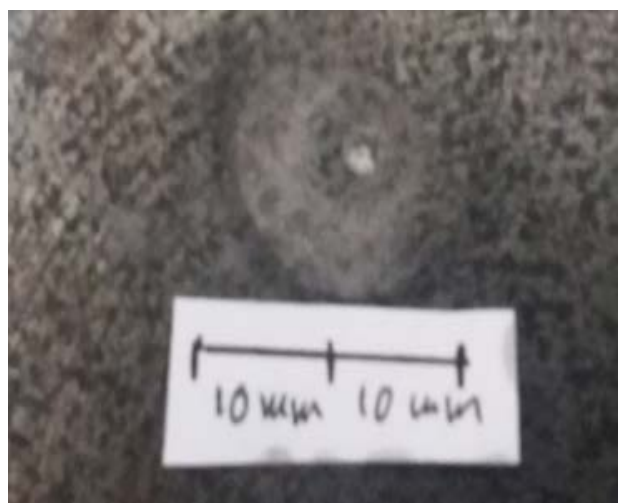

Gambar 7. Kerusakan Pada Pelat Baja AISI 4140 setelah Proses Hardening dengan tebal pelat 7 mm.

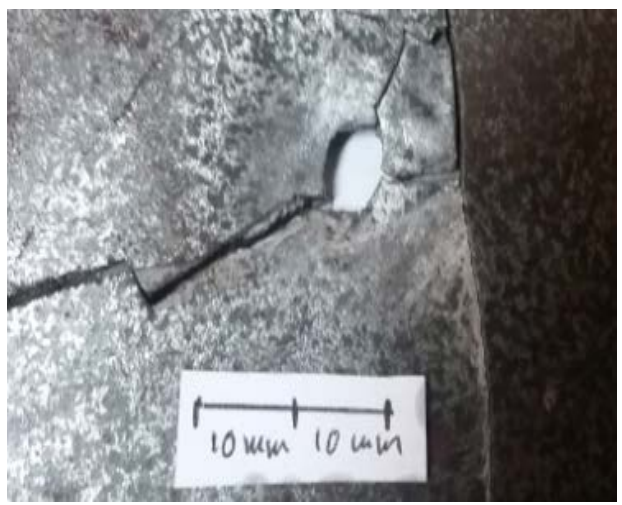

Gambar 8. Kerusakan Pada Pelat Baja AISI 4140 setelah Proses Hardening dengan tebal pelat 5 mm.

Bentuk kerusakan yang dihasilkan pada pelat akibat ditumbuk peluru dapat dilihat pada gambar 3 - 8 . Pada gambar 3 pelat AISI 4140 mampu menahan tembusan dari peluru yang ditembakkan dengan kecepatan 900 m/s. Pada bagian muka pelat (sebelah kiri) lubang yang dihasilkan adalah ductile hole. Sementara pada bagian belakang terlihat adanya smooth bulge. Terlihat adanya retak yang merambat dari area yang terkena impak peluru. Pada gambar 4 dan 5 , di bagian depat pelat baja karbon rendah dan baja tahan karat SS 304 terlihat adanya broken petal yang terbentuk. Juga terdapat adanya lip formation di sekeliling lubang. Sementara pada bagian belakang baja karbon rendah lubang yang terbentuk mulus dan bagian belakang baja tahan karat SS 304 terbentuk petal.

Ketika baja AISI 4140 ditingkatkan kekerasannya, pelat yang ditembak (tebal 7mm) hanya membentuk tanda bekas indentasi (lihat gambar 7). Di bagian tengah indentasi tersebut terlihat adanya bekas peluru yang menempel. Untuk pelat dengan tebal $5 \mathrm{~mm}$, hasil uji tembak menunjukkan pelat tidak mampu menahan peluru. Pelat mengalami pecah dimana retak dari pecahan tersebut menjalar dari lubang yang dihasilkan akibat penetrasi peluru (lihat gambar 8).

\section{KESIMPULAN}

Dari hasil yang telah dicapai dapat diambil kesimpulan sebagai berikut:

a. Baja AISI 4140 memiliki ketahanan balistik yang lebih baik bila dibandingkan dengan ketahanan balistik baja komersial lainnya, dimana pada ketebalan $9 \mathrm{~mm}$ mampu menahan penetrasi peluru kaliber 5,56 mm yang ditembakkan pada jarak 25 m dengan kecepatan tembak 900 m/s. 
b. Proses perlakuan panas hardening mampu meningkatkan ketahanan balistik baja AISI 4140 dan ketebalan minimum baja yang mampu menahan peluru adalah $7 \mathrm{~mm}$.

\section{REFERENSI}

[1] Jena PK, Mishra B, Kumar KS, Bhat TB. An experimental study on the ballistic impact behaviour of some metallic armour materials againts 7.62 mm deformable projectile. Materials \& Design 2010; 31: 3308-3316

[2] Maweja K, Stumpf W. The design of advanced performance high strength low-carbon martensitic armour steels, Part 1. Mechanical property considerations. Materials Science and Engineering A 2008; 485: 140-153.

[3] Jena PK,Mishra B, RameshBabu M, Babu A, Singh AK, Kumar KS, Bhat TB. Effect of heat treatment on mechanical and ballistic properties of a high strength armour steel. International Journal of Impact Engineering 2010; 37: 242-249.

[4] Mishra B, Jena PK, Ramakhrisna B, Madhu V, Bhat TB, Gupta NK. Effect of tempering temperature, plate thickness and presence of holes on ballistic impact behavior and ASB formation of a high strength steel. International Journal of Impact Engineering 2012; 44: 17-28.

[5] Kilic N, Ekici B. Ballistic resistance of high hardness armor steels against $7.62 \mathrm{~mm}$ armor piercing ammunition. Design 2013; 44: 35-48.

[6] Kilic N, Bedir S, Erdik A, Ekici B, Tasdermirci A, Guden, M. Ballistic behavior of high hardness perforated armor plates against $7.62 \mathrm{~mm}$ armor piercing projectile. Materials \& Design 2014; 63: 427-438.

[7] Senthil PP, Singh BB, Kumar KS, Gogia AK. Effect of heat treatment on ballistic performance of an armour steel againts long rod projectile. International Journal of Impact Engineering 2015; 80: 13-23.

[8] Jena PK, Senthil PP, Kumar SK. Effect of tempering time on ballistic performance of a high strength armour steel. Journal of Applied Research and Technology 2016; 14: 47-53.

[9] Ryan S, Lib H, Edgertond M, Gallardy D, Cimpoeru SJ. The ballistic performance of an ultra-high hardness armour steel: An experimental investigation. International Journal of Impact Engineering 2016; 94: 60-73.

[10] Dikshit SN, Kutumbrao VV, Sundararajan, G. The influence of plate hardness on the ballistic penetration of thick steel plates 1995; 2: 293-320

\section{Ucapan Terima Kasih}

Penulis mengucapkan banyak terima kasih kepada Departemen Teknik Mesin Undip yang telah mendukung kegiatan penelitian ini melalui Hibah Penelitian dari DIPA Fakultas Teknik Undip tahun anggaran 2016. 